\title{
Discussion on the Talent Cultivation Mode of "Excellent Engineer" Based on Cultivating the Capacity of Solving Complicated Engineering Problems
}

\author{
Xiangqin $\mathrm{Li}^{1}$, Yongcheng $\mathrm{Wu}^{2}$ \\ ${ }^{1}$ Computer Engineering School, Jingchu University of Technology Jingmen, China \\ lixiangqin_2012@163.com \\ ${ }^{2}$ Computer Engineering School, Jingchu University of Technology Jingmen, China \\ wuyongcheng11@126.com
}

\begin{abstract}
According to the excellent engineering cultivation plan, this paper has discussed the capacity that should be equipped for students to solve complicated engineering problems. Through analyzing domestic and overseas "excellent engineer" cultivation mode and existing problems, this paper has put forward the approach for realizing the "excellent engineer" talent cultivation mode for cultivating the capacity of solving complicated engineering problems. Meanwhile, according to the characteristics and cultivation objectives of computer science and technology major in Jingchu University of Technology, this paper explores and practices the talent cultivation mode.
\end{abstract}

Keywords-Complicated engineering problems; Excellent engineers; Cultivation mode; Innovation capacity

\section{INTRODUCTION}

The capacity of solving complicated engineering problems is the capacity that should be equipped for students majoring in undergraduate engineering; In Focusing on the Cultivation of Students' Capacity of solving Complicated Engineering Problems, Mr. Zongli Jiang clearly puts forward that the basic positioning for undergraduate engineering education is to cultivate the capacity for students to solve complicated engineering problems. In order to reinforce the cultivation of students' engineering capacity and innovation capacity, and our country puts forward "excellent engineer education cultivation plan" [1-2], and the objective is to cultivate a batch of highquality talents that possess innovation capacity and adapt to the development demands of economic society.

In Applying Research Learning to Cultivate Complicated Engineering Solving Capacity, Professor Jian Lin provides how to design complicated engineering problems applicable to research learning, and build complete problem complicity progressively increased research learning mode, so as to provide references for cultivating the complicate engineering solving capacity for the engineering specialty of colleges in our country[3-4], the proposal of Professor Lin is applicable to 985 colleges, and we still have a big difference with such requirements. As the newly built undergraduate college, due to

This research was supported by the Teaching Reform Program of Jingchu University of Technology (JX-201701). the short undergraduate school-running time, it is currently under the period of exploration considering the engineering education cultivation mode, and the talent cultivation mode is relatively simple, and still has some disadvantages in the cultivation of students' practical capacity and innovation capacity, etc. For instance, the course system, teaching contents and course evaluation method are backward. Thus, in order to adapt to the requirements for the cultivation of excellent engineers under the new situation, the newly built undergraduate colleges should reform the talent cultivation mode, and realize the talent cultivation mode taking the cultivation of students' capacity of solving complicated engineering problems as the core.

The exploration and research about the "excellent engineer" talent cultivation mode based on cultivating the capacity of solving complicated engineering problems can exert a positive effect on promoting the cultivation of innovation talents and improving school talent cultivation level. Through analyzing students' capacity of solving complicated engineering, it can be good for solving how to implement talent cultivation scheme, and clearing up what professional capacity should the full-time teachers possess and the cultivation of full-time teachers. On the contrary, through improving the teaching capacity of fulltime teachers, it can promote the cultivation of excellent engineers, the formulation of talent cultivation scheme and the construction of course system, improve the practical teaching quality, and then reinforce students' operational capacity, the capacity of solving actual problems and the innovation capacity. 
separated from the industrial enterprise demands; lack in the integral optimization of course system; slow textbook upgrading, and the contents of some textbooks lag behind scientific and technical development and engineering practice; lack in talent cultivation mode quality evaluation system.

\section{A. Overseas "Excellent Engineering” Cultivation Mode}

The overseas "excellent engineer" cultivation mode mainly includes "industry-university cooperation", "enterprise teaching", "dual system", "work-study program" and "teaching factory" and other modes [6]. The cultivation mode is as shown in Table 1.

"Industry-university cooperation" refers to universities cultivating and incubating enterprises, and then establishing cooperation relationship; the cooperation with enterprises is regarded as a part for improving the academy and scientific research in universities, so that teaching, scientific research and talent cultivation can be sufficiently connected, which can not only cultivate high-quality talents for colleges, but also obtain scientific research achievements.

The "enterprise teaching" mode refers to enterprises setting talent cultivation school, and the relevant courses to cultivate talents; "dual system" mode refers to taking theoretical teaching as the basis, alternatively implementing teaching activities in schools and enterprises, and cultivating appliedtype high-quality talents meeting the requirements of the two parties; "work-study program" mode refers to alternatively arranging students' course learning and work practice, so that students can at least have half the time to be engaged in the practice work at enterprises, and truly realize the linkage of theory with practice. The "teaching factory" mode refers to introducing the enterprise production operation link into the teaching activity, and let students experience the actual work process of enterprises in teaching.

TABLE I. OVERSEAS “EXCELlENT ENGINEER” Cultivation Mode

\begin{tabular}{|c|c|c|}
\hline Cultivation Mode & Typical Representatives & Characteristics \\
\hline $\begin{array}{l}\text { Industry-university } \\
\text { cooperation }\end{array}$ & $\begin{array}{l}\text { America Stanford University and } \\
\text { Silicon Valley }\end{array}$ & $\begin{array}{l}\text { Universities incubate enterprises, and then } \\
\text { constantly cooperate with enterprises }\end{array}$ \\
\hline Enterprise teaching & Japan & $\begin{array}{l}\text { Enterprises set talent cultivation school, and set } \\
\text { courses }\end{array}$ \\
\hline Dual system & Germany & $\begin{array}{c}\text { Alternately conduct teaching activities in schools } \\
\text { and enterprises }\end{array}$ \\
\hline Work-study program & Canada University of Waterloo & $\begin{array}{l}\text { Alternative arrangement of school learning and } \\
\text { work practice }\end{array}$ \\
\hline Teaching factory & Singapore universities & $\begin{array}{l}\text { Introduce modernized operation management } \\
\text { concept into schools }\end{array}$ \\
\hline
\end{tabular}

\section{B. Domestic “Excellent Engineer" Cultivation Mode}

In the Construction of Talent Cultivation System Based on Excellent Engineer Education Cultivation Plan, Yuyang Zhao team emphasizes on reinforcing the cultivation of students' engineering practice capacity through school-enterprise cooperation " $3+1$ " cultivation mode. Currently, the domestic "excellent engineer" cultivation mode mainly has three types [7-8]: firstly, it is the enterprise customization mode, such as "Blue Bridge Class". In the former two years, students complete basic course and professional basis course learning at school, and then in the third year, they will learn about the professional courses related to the customized enterprises, and then in the fourth year, they will enter into enterprises for practice. Secondly, it is the practice base cultivation mode. " $3+1$ " teaching mode is adopted, and in the former 3 years, students will complete the basic course and professional course learning at school, and then enter into practice base for practical training in the fourth year. Thirdly, it is industry- 
university-research cultivation mode. Generally, it is driven by scientific research projects, especially take the horizontal project of enterprises as the basis, and then rely on the laboratories at school and the production site of enterprises, to complete the cultivation of "excellent engineers".

Although domestic "excellent engineer" cultivation mode has obtained some success, there are still some problems: the teacher resources possessing engineering practice background are insufficient, the degree for enterprises to participate in college talent cultivation is insufficient and the implementation of engineering practice link is difficult.

\section{SPECIFIC PRACTICE FOR THE "EXCELLENT ENGINEER" TAlent Cultivation MOdE FOR Cultivating THE CAPACITY OF SOLVING COMPLICATED ENGINEERING PROBLEMS}

\section{A. Optimize Course System}

As per the course type, it is applicable to adjust the course starting semester, and in order to highlight practicalness, it is also applicable to appropriately decrease theoretical teaching hours, increase practical teaching hours, such as the course experiment, course design and comprehensive practice. Along with the fast development of information technology and the introduction of big data concept, the original course system can no longer meet social demands, so it is requested to extend the original course system. Taking the computer science and technology specialty of our school as an example, it is applicable to build core course systems adapting to the big data engineering capacity cultivation on the basis of the original course system, as shown in Figure 1.

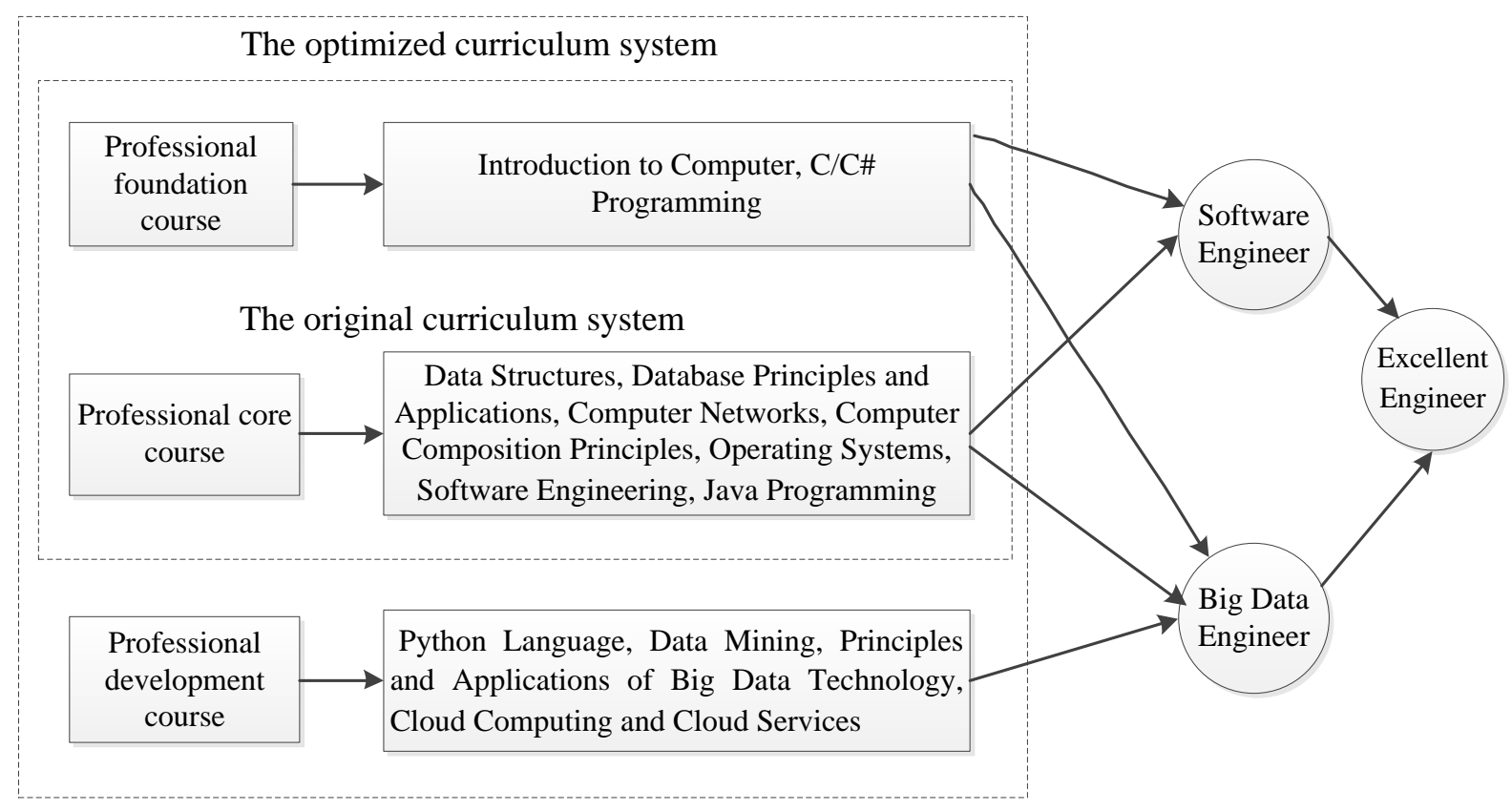

Fig. 1. Course System Adapting to Big Data Engineering Capacity Cultivation

\section{B. Reinforce the Cultivation of Engineering Practice \\ Capacity}

It is applicable to introduce CDIO project teaching method [9], and then on the basis of the project teaching method, build corresponding cultivation system as per CDIO teaching concept in combination with the discipline background and characteristics of the school; on one hand, it can make students mater professional knowledge; on the other hand, it can cultivate students' practical capacity, innovation capacity and team cooperation capacity. Taking $\mathrm{C} \#$ program design course as an example, as per the teaching outline requirements in combination with the textbook teaching contents, the abstract contents of $\mathrm{C \#}$ program design courses are decomposed into specific project tasks, as shown in Table 2. 
TABLE II. Course Project TASk Design

\begin{tabular}{|c|c|c|}
\hline Project No. & Task Name & Course Knowledge Point \\
\hline 1 & $\begin{array}{l}\text { The first control panel } \\
\text { application program }\end{array}$ & $\begin{array}{l}\text { Visual studio programming environment, interface } \\
\text { and control property }\end{array}$ \\
\hline 2 & Deposit calculator & $\begin{array}{c}\text { type, constant, variable, operational character and } \\
\text { expression Data }\end{array}$ \\
\hline 3 & Ticket sales calculator & If statement and switch statement \\
\hline 4 & Performance counter & $\begin{array}{l}\text { For statement, while statement, do while statement } \\
\text { and foreach statement }\end{array}$ \\
\hline 5 & Performance ranking system & One-dimensional or two-dimensional array \\
\hline 6 & Gluttonous Snake & Type, object, field, attribute and method \\
\hline 7 & $\begin{array}{l}\text { Four arithmetic operations } \\
\text { calculator }\end{array}$ & Method and keyboard events \\
\hline 8 & Contact management & ADO.NET database access technology \\
\hline
\end{tabular}

\section{Establish "Learning through Racing” Cultivation Mode}

Discipline competition can be used to drive learning, and competition can form good learning mode, and meanwhile, improve teachers' teaching level, and realize the promotion of teaching with competition. Such teaching mode that uses competition as the carrier to cultivate students' capacity has obtained a good effect. For instance, in July, 2017, it obtained the Golden Prize of the 3rd China "Internet+" College Students Innovation and Entrepreneurship Competition Hubei Provincial Competition Area. In September, 2017, it obtained the Third Prize of Hubei Provincial 2nd Network Safety Technology Competition. Thus, the promotion of learning, teaching, and construction with competition can not only promote the construction of learning styles and teaching styles at school, but also cultivate students' operation capacity, communication capacity, and team cooperation capacity. Through such practical combat and competition mechanism, it can give full play to students' subjective initiative, reinforce the learning interest, improve practical capacity and innovation capacity, realize the seamless connection of talent cultivation and enterprise demand, and finally let students reach to the cultivation requirements of an excellent engineer.

\section{Establish On-campus Tutor System and School-enterprise Joint Cultivation Mode}

One full-time teacher can guide 5-10 students in learning professional courses, participating in discipline competitions, certification examinations and innovation activities, and meanwhile, let students participate in the tutors' scientific research or engineering projects. On the other hand, students can also participate in the $\mathrm{R} \& \mathrm{D}$ of engineering projects at the enterprises recommended by their tutors, so as to improve the scientific research capacity and innovation capacity, and then form the integration of teaching, scientific research and production.

Meanwhile, build "excellent engineer" cultivation class and enterprise cooperation, and annually receive 30-50 students, carry out "order-type" talent cultivation, and jointly formulate talent cultivation scheme.

\section{E. Establish High-level Teacher Team of Engineering Practice and Experiment}

Universities will appoint full-time teachers to enterprises to participate in the actual engineering project there or conduct domestic and overseas academic visits, and then enrich their engineering practice experience. Meanwhile, they will hire excellent engineers or doctors with engineering background oriented to the society and enterprises to take part-time jobs at the school, participate in the formulation of talent cultivation plan, and guide students' practice, experiment, practical training and other practical teaching. Thus, the engineering practice teaching team is constructed under the lead of professors with rich engineering education experience, senior engineers of enterprises or corporate executives.

\section{F. Cultivation Mode and Teaching Management Reform}

As per the cultivation mode and teaching management characteristics, it takes the computer science and technology specialty of our school as an example, and then puts forward the "excellent engineer" talent cultivation mode for cultivating the capacity of solving complicated engineering problems, and then adopts " $2+1+1$ " mode, and for undergraduate students, they will complete the basic course and professional course learning in the former two years, and then enter into the scientific research team of the tutor in the third academic year, and mainly complete the professional core course learning, and then in the fourth academic year, they will enter into enterprises for engineering practice and cultivate the practical capacity and comprehensive quality capacity. 


\section{SUMMARY}

Specific to the basic requirements of excellent engineers and the social development demands, it is oriented to the objective of cultivating the capacity of solving complicated engineering problems, and then constantly explores new teaching methods and cultivation mode, builds professional knowledge system and multi-layer engineering practice teaching system, and meanwhile, through focusing on these modules, carry out a series of teaching reform, teacher team construction, industry-university cooperation and collaboration talent cultivation and other measures, it strives to explore and build the teaching system meeting the excellent plan, and constantly innovates talent cultivation mode.

\section{REFERENCES}

[1] Yan Zhang and Xiaoling Wen. Industry-university-research Cooperation New Mode Based on "Excellent Plan" Background [J]. College Education, 2012, (5): 20-21.

[2] Qiyuan Chen. Recognition about Implementing Some Problems about the "Excellent Engineer Education Cultivation Plan" Work [J]. China University Teaching, 2012, (1):4-6.

[3] Jian Lin. Form the Excellent Engineer Cultivation Characteristics Forming Competitive Advantages [J]. Researches in Higher Education of Engineering. 2012, (6):7-21.

[4] Jian Lin. Analysis on the "Excellent Engineer Education Cultivation Plan" Quality Evaluation Based on Engineering Education Certification [J]. Researches in Higher Education of Engineering. 2014, (5): 35-44.

[5] Guangxu Cheng. Striving to Realize the New Breakthrough of Talent Cultivation Mode Reform. China Higher Education [J]. 2009, (1). 24-24.

[6] Jianhua Tao, Zhongmin Xiao, Wu Deng and Sikun You. Comparison of School-enterprise Cooperation "Excellent Engineer" Cultivation Mode. Education Teaching Formula [J]. 2017, (1): 176-177.

[7] Wei Liu, Xiaorong He and Juan He. Analysis on the Cultivation Mode of Excellent Engineers for Electrical Engineering and Automation Specialty [J]. China Electric Power Education, 2012, (6): 58-59.

[8] Zhi Yang, Rongjun Chen, Qingyuan Xu, Junying Yuan and Haishan Chen. Discussion about the Cultivation Mode of Excellent Engineer for Electronic Information [J]. Journal of Wuhan University (Natural Science Version). 2012, (10): 9-12.

[9] Shihui Zhang, Yun Qi and Wei Yan. Course Reform Practice about the Excellent Engineer Order Class Based on CDIO [J]. Researches in Higher Education of Engineering. 2014, (5): 187-190. 